\title{
Use of glycosylated haemoglobin as diagnostic tool in Greenland: prevalence of diagnosed diabetes mellitus
}

\author{
Line Damsgaard ${ }^{1}$ and Michael Lynge Pedersen ${ }^{1,2^{*}}$
}

\begin{abstract}
Background: The prevalence of undiagnosed diabetes mellitus (DM) in Greenland has been reported very high with only 30\% of cases diagnosed. In 2010, glycosylated hemoglobin (A1C) was introduced as a diagnostic tool in Greenland. However, the current use of A1c is unknown as well as the current prevalence of diagnosed DM. The aim of this study was firstly to estimate the use of A1C as diagnostic tool within the first 27 months after introducing the method and secondly to estimate the age and gender specific prevalence of diagnosed DM in Greenland in 2012.
\end{abstract}

Methods: This study was perfomed as a cross-sectional register study using data from electronic medical records (EMR). To analyse the use of A1C as diagnostic tool:

A sample amongst all Greenlanders at or above age 35 old was used to determine the number of individuals screened with A1C within a 27 month period, excluding those already known to have DM.

To estimate the prevalence of diagnosted DM: Patients with DM were identified electronically using a statistic module run on data in the EMR. Age and gender specific prevalence was estimated using the Greenlandic population as of 1 January 2012 as the background population.

Results: The test sample resulted in a study group of 1008 individuals from which 2.3\% (23) were excluded because they were already known to have DM. Among the remaining 985, 13.6\% were tested with A1C at least once during the 27 months of observation. DM was diagnosed in $7.5 \%(10)$ of the tested persons and in $1.0 \%$ of the whole group.

Regarding prevalence, a total of 920 patients with diagnosed DM were identified. The total prevalence among adults aged 20-79 years old was 2.20\% (95\% Cl: 2.05-2.34) with no significant difference between genders.

Conclusion: Testing for DM using A1C as diagnostic tool is used in Greenland. The prevalence of diagnosed DM in Greenland remains low although increasing. Undiagnosed DM may still be an important issue in Greenland.

Keywords: Diabetes mellitus, Greenlanders, Inuit, Haemoblobin A1C, Glycohemoglobin

\section{Introduction}

Greenland has undergone a rapid transition during the last half century from a traditional Inuit society dominated by small communities, villages and settlements to a modern society [1]. Within a few decades (1950s to 1970s), Greenland was transformed from a traditional hunting society to a modern society where most people

\footnotetext{
*Correspondence: milp@peqqik.gl

'Queen Ingrid Health Care Center, Nuuk, Greenland

${ }^{2}$ Greenland Center for Health Research, University of Greenland, Nuuk, Greenland
}

now rely on wage earning [1]. These profound social and cultural change have been followed by a health transition with an increasing prevalence of lifestyle related diseases like overweight, obesity, diabetes and ischemic heart diseases [2-7] similar to what has occured among Inuit in Alaska and Canada [8-10].

Thus, diabetes mellitus (DM) used to be very rare (less than $1 \%$ of the population) in Greenland [11]. However, epidemiological studies have indicated a high prevalence of diabetes at around ten percent among adult Greenlanders based on oral glucose tolerance tests [6]

\section{Biomed Central}


comparable to levels among Inuit and Native Indian populations in Canada and Alaska [12-15]. However, seventy to eighty percent of cases were undiagnosed indicating low diagnostic activity $[6,16]$.

In 2008, a national diabetes program was implemented in the primary health care system in Greenland aiming to improve the diabetes care including diagnostic activity and screening for diabetic complications. Along with increasing quality of care, the prevalence of diagnosed type 2 diabetes mellitus (T2DM) rose by $19 \%$ within two years from $1.97 \%$ to $2.3 \%$ among adult Greenlanders at or above 40 years old [17]. However, the prevalence of diagnosed T2DM was still much lower than reported in the surveys of the population $[6,16]$.

In order to optimize the diagnostic procedure of diabetes and to make case finding more feasible in Greenland, the diagnostic strategy was changed by the first of June 2010 . From that date glycosylated hemoglobin (A1C) was introduced as a screening tool $[18,19]$ in Greenland consequently replacing the former use of fasting whole blood glucose testing [20]. Neither the diagnostic activity nor the prevalence of diagnosed diabetes mellitus has been evaluated after the introduction of $\mathrm{A} 1 \mathrm{C}$ as a diagnostic tool.

The aim of this study was first to describe within the first twenty-seven months after introducing $\mathrm{A} 1 \mathrm{C}$ as a diagnostic strategy the diagnostic activity with $\mathrm{A} 1 \mathrm{C}$ as a screening tool and second, to estimate the age and gender specific prevalence of diagnosed diabetes mellitus in Greenland in 2012.

\section{Materials and methods}

The study was designed as two cross-sectional observational register studies of the Greenlandic population. Observational data were collected retrospectively through the Electronic Medical Record (EMR) implemented throughout the whole Greenlandic primary health care system in the autumn of 2007.

\section{Setting}

Greenland is the largest island in the world covering an area of over 2 million $\mathrm{km}^{2}$ [21]. The country is sparsely populated with approximately 56,000 inhabitants living along the coast in 18 towns and around 60 minor settlements. Furthermore, the country is divided into 4 governmental regions and 5 health regions [22]. Approximately $90 \%$ of the population is of Greenlandic origin (native Inuit); the last $10 \%$ are immigrants (mostly Danes) [21].

Primary health care is free to all inhabitants and provided locally in primary health care clinics. Since 2008 all patients diagnosed with diabetes mellitus have been coded with "D" in the EMR.

Measurements of $\mathrm{A} 1 \mathrm{C}$ were performed at The Central Laboratory at Queen Ingrid Hospital in Nuuk, using Architecht $^{\circ}$ 8000 $\mathrm{T}$ (Abbott Laboratories) based on an enzymatic technique. The Central Laboratory is a member of the Danish quality control system for laboratories, DEKS. In addition some of the analyses of $\mathrm{A} 1 \mathrm{C}$ have been performed locally using DCA vantage ${ }^{\circ}$ (Siemens Healthcare Diagnostics) based on an immunological technique. Results of the tests were recorded in the electronic lab card for Greenland (BBC) and/or directly in the lab card in the EMR. A confirmed value of $\mathrm{A} 1 \mathrm{C}$ at or above $48 \mathrm{mmol} / \mathrm{mol}(6.5 \%)$ is used as diagnostic for diabetes mellitus in Greenland as recommended by the American Diabetes Association [18].

\section{Study populations and analysis \\ Use of A1C as diagnostic tool - study sample 1}

The first study population was defined as anyone affiliated with a primary health clinic in Greenland, who was born on the 1st of any month of the year before first of January 1978. Thus only adults at or above 35 years old where included.The cut-off age was chosen because most cases of undiagnosed diabetes in Greenland occur among adults $[6,16]$. We registered their age and gender. Individuals who were diagnosed with diabetes (coded with "D") in their medical record before 1st of June 2010 were excluded from the study group. Among the remaining study sample we registered the number of persons screened with $\mathrm{A} 1 \mathrm{C}$ and the number of persons who were actually diagnosed with diabetes during the 27 months period. The proportion of persons without diagnosed diabetes that was screened with $\mathrm{A} 1 \mathrm{C}$ within the study period was used to describe the diagnostic activity.

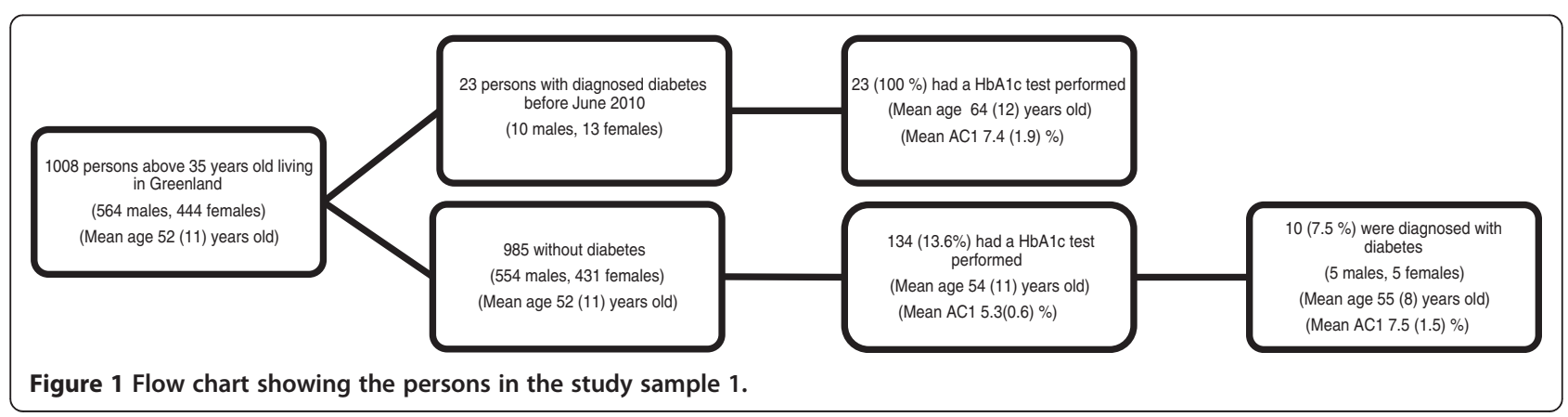


Prevalence of diagnosed diabetes mellitus -study sample 2

The second study population was identified as all patients coded with " $\mathrm{D}$ " in the EMR using an electronically search module (data extraction September 2012). The age and gender specific prevalence was calculated using the Greenlandic population as of 1 January 2012 as the background population [21]. The prevalence of diagnosed diabetes mellitus among adults at or above 20 years old was estimated in the present study (2012) - as well as for 2008 and 2010 studies-based on data published in 2011 [17].

\section{Statistics}

Crude prevalence was reported for age and gender specific groups using 95\% confidence intervals. Chi-square tests were used to compare frequencies between two groups, and chi-square tests for trends were used to examine prevalence rates with increasing age and over time. P-value at 0.05 was used as level of significance. The ethics committee for medical research in Greenland has approved the study with reference number 2013-5.

\section{Results}

Use of A1C as diagstic tool - study sample

A total of 1008 individuals born before the first of January 1978 on the first day of a month, living in Greenland as of September 2012 were identified (see Figure 1). Of those, $2.3 \%$ (23) were diagnosed with diabetes mellitus before the study period (before the first of June 2010). Among the remaining 985 individuals, 13.6\% (134) were tested for diabetes mellitus utilizing measurement(s) of $\mathrm{A} 1 \mathrm{C}$ at least once during the 27 months of observation. Diabetes mellitus was diagnosed in $7.5 \%$ (10) of the tested persons and in $1.0 \%$ of the whole group (985).

\section{Prevalence of diagnosed diabetes mellitus -study sample 2}

A total of 920 patients with diagnosed diabetes mellitus were identified. The age and gender specific prevalences of diabetes mellitus are illustrated in Table 1 and Figure 2. The total prevalence among adults aged 20-79 years old was $2.20 \%$ (95\% CI: 2.05-2.34) with no significant difference between the genders $(p=0.945)$. The prevalence increased with age for both males $(\mathrm{p}<0.001)$ and females $(\mathrm{p}<0.001)$. The prevalence among patients at or above 20 years old documented in this study is illustrated in Table 2 together with prevalence calculated from earlier published data [17]. The prevalence of diagnosed diabetes mellitus is still increasing in Greenland $(\mathrm{p}<0.001)$.

\section{Discussion}

The principal finding in this study was that $13.6 \%$ of adults at or above 35 years have been tested for diabetes using $\mathrm{A} 1 \mathrm{C}$ as the diagnostic tool, indicating that $\mathrm{A} 1 \mathrm{c}$ is used as a diagstic tool in Greenland in this age group.
Table 1 Age and gender specific prevalence of diabetes mellitus in Greenland

\begin{tabular}{|c|c|c|c|}
\hline Age (years) & $\begin{array}{c}\text { Male } \\
\text { Prevalence \% } \\
(\mathrm{n} / \mathrm{N})(95 \% \mathrm{Cl})\end{array}$ & $\begin{array}{c}\text { Female } \\
\text { Prevalence \% } \\
(\mathrm{n} / \mathrm{N})(95 \% \mathrm{Cl})\end{array}$ & $\mathbf{P}$ \\
\hline \multirow[t]{3}{*}{$0-9$} & 0.0 & 0.0 & \\
\hline & (0/4205) & (0/3936) & - \\
\hline & $(0.0-0.0)$ & $(0.0-0.0)$ & \\
\hline \multirow[t]{3}{*}{$10-19$} & 0,1 & 0,0 & \\
\hline & $(4 / 4322)$ & $(0 / 4297)$ & 0.046 \\
\hline & $(0.0-0.2)$ & $(0.0-0.0)$ & \\
\hline \multirow[t]{3}{*}{$20-29$} & 0,1 & 0,1 & \\
\hline & $(6 / 4530)$ & $(6 / 4317)$ & 0.933 \\
\hline & $(0.0-0.2)$ & $(0.0-0.3)$ & \\
\hline \multirow[t]{3}{*}{$30-39$} & 0,5 & 0,3 & \\
\hline & $(17 / 3757)$ & $(11 / 3237)$ & 0.457 \\
\hline & $(0.2-0.7)$ & $(0.1-0.5)$ & \\
\hline \multirow[t]{3}{*}{$40-49$} & 1,3 & 1,4 & \\
\hline & $(66 / 5210)$ & $(60 / 4414)$ & 0.691 \\
\hline & $(1.0-1.6)$ & $(1.0-1.7)$ & \\
\hline \multirow[t]{3}{*}{$50-59$} & 3,3 & 2,8 & \\
\hline & $(150 / 4575)$ & $(101 / 3555)$ & 0.258 \\
\hline & $(2.8-3.8)$ & $(2.3-3.4)$ & \\
\hline \multirow[t]{3}{*}{$60-69$} & 6,8 & 9,3 & \\
\hline & $(167 / 2452)$ & $(111 / 1753)$ & 0.538 \\
\hline & $(5.8-7.8)$ & $(5.2-7.5)$ & \\
\hline \multirow[t]{3}{*}{$70-79$} & 9,0 & 10,8 & \\
\hline & $(81 / 903)$ & $(95 / 900)$ & 0.257 \\
\hline & $(7.1-10.8)$ & $(8.5-12.6)$ & \\
\hline \multirow[t]{3}{*}{$80+$} & 9,5 & 9,4 & \\
\hline & $(16 / 169)$ & $(29 / 308)$ & 0.985 \\
\hline & $(5.1-13.9)$ & $(6.2-12.7)$ & \\
\hline \multirow[t]{3}{*}{$20-79$} & 2,3 & 2,1 & \\
\hline & $(487 / 21427)$ & (384/18176) & 0.279 \\
\hline & $(2.1-2.5)$ & $(1.9-2.3)$ & \\
\hline
\end{tabular}

Approximately, $7.5 \%$ of the tested persons were diagnosed with diabetes mellitus indicating that undiagnosed diabetes mellitus is still an issue and active case-finding searches relevant. Furthermore, the prevalence of diagnosed diabetes mellitus in Greenland documented in this study is the highest reported so far indicating increasing prevalence.

\section{Strength and weakness}

The major strength in this study was that the whole population of Greenland was included. All A1C test results were to be found in the EMR. Case finding using 


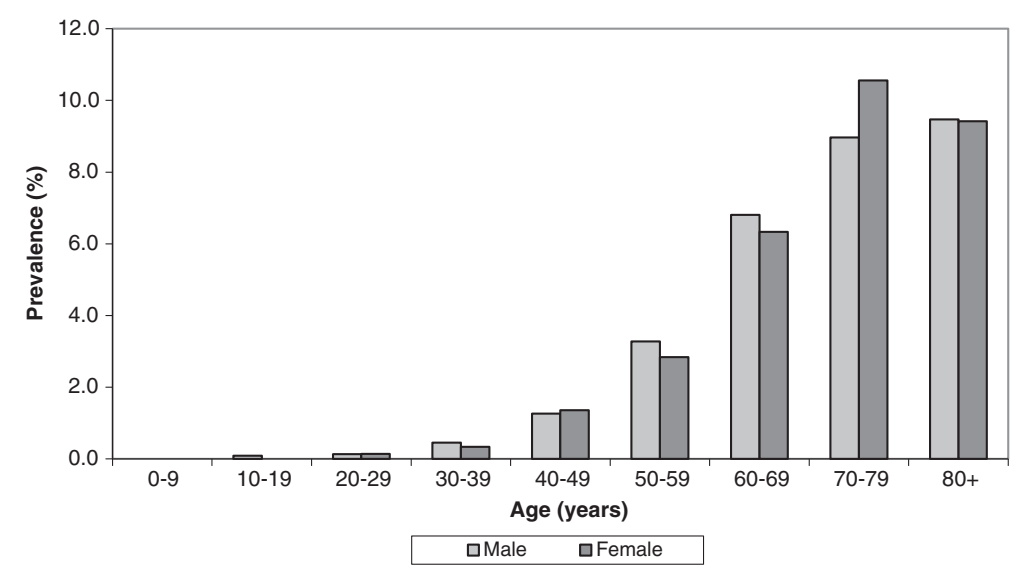

Figure 2 Age and gender specific prevalence of diabetes mellitus in Greenland 2012.

whole blood capillary glucose was not included in this study. The actual number of patients tested for diabetes in the study period may therefore be underestimated. Furthermore, the increasing prevalence of diagnosed diabetes observed in the study period reflects the whole diagnostic activity in Greenland and not only the A1C diagnostic activity. Use of whole blood capillary testing may also have contributed to the diagnostic process because new guidelines can not be implemented immediately nationally.

Another limitation in this study is the unknown diagnostic activity of diabetes mellitus before introducing the A1C. Thus, the results mainly describe baseline diagnostic activity in Greenland after implementation of the new diagnostic criteria.

A possibly weakness in this study concerns the estimation of the prevalence of diagnosed diabetes mellitus. Only patients that were actually coded with " $\mathrm{D}$ " in the electronic medical record were included in the study. This may lead to an underestimation of the true prevalence of diagnosed diabetes mellitus. However, patients without a "D" code who receive prescriptions electronically for glucose lowering drugs, have their medical record reviewed annually, a process intended to identify patients with diabetes yet no " $\mathrm{D}$ " code. Thus the underestimation is not likely to be of any significant magnitude.

\section{Use of $\mathrm{A} 1 \mathrm{C}$ as diagstic tool}

The use of $\mathrm{A} 1 \mathrm{C}$ as diagnostic toolwithin the first 27 month after introducing the new strategy underlines the feasibility in a Greenlandic context of using this method.
A1C testing can be performed in contrast to fasting whole blood glucose tests or oral glucose tolerance tests without the delay of waiting on fasting individuals. On the other hand it is obvious that the diagnoses using A1C criteria are not exactly the same as those diagnosed on plasma glucose [19,23-25]. Also, ethnical differences have been suggested as proving problematic when using HbA1c diagnosis. Thus, in most cases a lower number of patients are diagnosed using $\mathrm{A} 1 \mathrm{C}$ criteria than when using oral glucose tolerance tests. This discrepancy has also been demonstrated among Greenlanders where the prevalence of diabetes based on oral glucose tolerance test resulted in $7.0 \%$ compared to $3.9 \%$ using the $\mathrm{A} 1 \mathrm{C}$ criteria [24]. Similary, the prevalence of diabetes based on oral glucose tolerance compared to A1C criteria was higher in United Kingdom (3.7\% versus 1.0\%), Australia (4.0\% versus $0.7 \%$ ) and Kenya (3.4\% versus $1.4 \%$ ) while the opposite was the case in Denmark $(4.2 \%$ versus 6.7\%) and India (10.2 5 versus $12.9 \%$ ) [24].

However, the obvious convenience of A1C might increase the number of patients tested and diagnosed with diabetes tested [23]. Furthermore, it seems evident that the most severe cases and consequently those that might benefit most from treatment are those that are diagnosed using A1C [26-29]. Using A1C as a diagnostic tool instead of the former use of whole blood capillary glucose (and not plasma glucose as recommended internationally) brings the diagnostic procedure in accordance with the most recent international guidelines [18].

Finally, in a sparsely populated country like Greenland with small health care units with a fluctuating health care

Table 2 Prevalence of diagnosed diabetes mellitus among adults at or above 20 years old in Greenland 2008-2012

\begin{tabular}{lllll}
\hline Year & $\mathbf{2 0 0 8}^{*}$ & $\mathbf{2 0 1 0}^{*}$ & $\mathbf{2 0 1 2}$ & $\mathbf{P}$ \\
\hline $\begin{array}{l}\text { Prevalence (\%) among adult at or above 20 years old } \\
\text { (number of patients/population) }\end{array}$ & 1.41 & 1.85 & 2.29 & $<0.001$ \\
& $(487 / 34,472)^{* *}$ & $(721 / 39,008)$ & $(916 / 40,080)$ \\
\hline
\end{tabular}

*[19] **Ninety percent of the population included in 2008. 
staff, it is imperative to have a very feasibly and reliable diagnostic setup for an upcoming disease like diabetes.

\section{Prevalence of diagnosed diabetes mellitus}

Increasing prevalence of diabetes is seen all over the world. In accordance with that we have found an increasing prevalence in this study compared to previous studies [17].

The increase has been documented withih the last five years and is most likely due to increased diagnostic activity. Improved treatment and increased survival among patients with diabetes along with an actual increase in the prevalence can also contribute to an increasing overall prevalence.

However, in a global perspective the prevalence of diagnosed diabetes remains quite low [30]. Undiagnosed patients still seem to be quite common. Perhaps therefore the $7.5 \%$ of individuals tested for DM were actually diagnosed with DM, which could indicate that the overall percentage of undiagnosed patients with DM was around $7.5 \%$ - around the double of the prevalence of diagnosed DM However, most likely, the individuals tested with $\mathrm{A} 1 \mathrm{C}$ are not a random sample of the population and rather represent individuals with increased risk of diabetes, making the percentage of undiagnosed cases among the total population less than $7.5 \%$.

\section{Conclusion}

In conclusion, testing for DM using $\mathrm{A} 1 \mathrm{C}$ as diagnostic tool is used in Greenland. The prevalence of diagnosed DM in Greenland although increasing remains low in a global perspective. Undiagnosed DM may still be an important issue in Greenland.

\section{Abbreviations}

DM: Diabetes mellitus; A1C: Haemoblobin A1C; Cl: Confidence intervals; EMR: Electronic medical record.

\section{Competing interests}

The authors have no competing interest to declare.

\section{Authors' contributions}

The study was designed by MLP. Both LD and MLP participated equeally in the analysis of data. First draft of the manuscript was carried out by LD and rewritten by MLP. Both authors read and approved the final manuscript.

\section{Acknowledgement}

We want to thank Anna Rask Lynge for her careful help with collection of data.

Received: 26 June 2013 Accepted: 7 October 2013

Published: 9 October 2013

\section{References}

1. Bjerregaard P, Young TK: The circumpolar Inuit - health of a population in transition. Copenhagen: Munksgaard; 1998.

2. Bjerregaard P, Young TK, Dewailly E, Ebbesson SO: Indigenous health in the Arctic: an overview of the circumpolar Inuit population. Scand J Public Health 2004, 32:390-395.

3. Curtis $T$, Kvernmo $S$, Bjerregaard $P$ : Changing living conditions, life style and health. Int J Circumpolar Health 2005, 64:442-450.
4. Bjerregaard P, Curtis T, Borch-Johnsen K, Mulvad G, Becker U, Andersen S, Backer V: Inuit health in Greenland: a population survey of life style and disease in Greenland and among Inuit living in Denmark. Int J Circumpolar Health 2003, 62:3-79.

5. Bjerregaard P, Aidt EC: Life conditions, lifestyle and health - population surveys in Greenland 2005-2009. [Danish and Greenlandic]. Copenhagen: University of Southern Denmark; 2010:1-30.

6. Jørgensen ME, Bjerregaard $P$, Borch-Johnsen $K$, Backer $V$, Becker $U$, Jørgensen $T$, et al: Diabetes and impaired glucose tolerance among the Inuit population of Greenland. Diabetes Care 2002, 25:1766-1771.

7. Jørgensen ME, Bjerregaard P, Kjaergaard JJ, Borch-Johnsen K: High prevalence of markers of coronary heart disease among Greenland Inuit. Atherosclerosis 2008, 196:772-778.

8. Ebbesson SO, Adler Al, Risica PM, Ebbesson LO, Yeh JL, Go OT, Doolittle W, Ehlert G, Swenson M, Robbins DC: Cardiovascular disease and risk factors in three Alaskan Eskimo populations: the Alaska-Siberia project. Int J Circumpolar Health 2005, 64:365-386.

9. Howard BV, Comuzzie A, Devereux RB, Ebbesson SO, Fabsitz RR, Howard WJ, Laston S, MacCluer JW, Silverman A, Umans JG, Wang H, Weissman NJ, Wenger CR: Cardiovascular disease prevalence and its relation to risk factors in Alaska Eskimos. Nutr Metab Cardiovasc Dis 2010 20:350-358

10. Chateau-Degat ML, Dewailly E, Noël M, Valera B, Ferland A, Counil E, Poirier $P$, Egeland GM: Hypertension among the Inuit from Nunavik: should we expect an increase because of obesity? Int J Circumpolar Health 2010, 69:361-372.

11. Pedersen ML: Diabetes mellitus in Greenland. Dan Med J 2012, 59:B4386.

12. Young TK, Schraer CD, Shubnikoff EV, Szathmary EJ, Nikitin YP: Prevalence of diagnosed diabetes in circumpolar indigenous populations. Int J Epidemiol 1992, 21:730-736.

13. Young TK, Reading J, Elias B, O'Neil JD: Type 2 diabetes mellitus in Canada's first nations: status of an epidemic in progress. CMAJ 2000, 163:561-566.

14. Naylor JL, Schraer CD, Mayer AM, Lanier AP, Treat CA, Murphy NJ: Diabetes among Alaska Natives: a review. Int J Circumpolar Health 2003, 62:363-387.

15. Ebbesson SO, Schraer CD, Risica PM, Adler Al, Ebbesson L, Mayer AM, Shubnikof EV, Yeh J, Go OT, Robbins DC: Diabetes and impaired glucose tolerance in three Alaskan Eskimo populations. The Alaska-Siberia Project. Diabetes Care 1998, 21:563-569.

16. Jørgensen ME, Borch-Johnsen K, Witte DR, Bjerregaard P: Diabetes in Greenland and its relationship with urbanization. Diabet Med 2012, 29:755-760.

17. Pedersen $\mathrm{ML}$, Jacobsen $\mathrm{J}$ : Improvement of diabetes care in a small but geographically widely spread population in Greenland. Effects of a national diabetes care programme. Diabet Med 2011, 28:1425-1432.

18. American Diabetes Association: Diagnosis and classification of diabetes mellitus. Diabetes Care 2010, 33(Suppl 1):S62-S69.

19. Bennett CM, Guo M, Dharmage SC: $\mathrm{HbA}(1 \mathrm{c})$ as a screening tool for detection of Type 2 diabetes: a systematic review. Diabet Med 2007, 24:333-343.

20. Alberti KGMM, Zimmet PZ: Definition, diagnosis and classification of diabetes mellitus and its complications. Report of WHO consultation, Part 1: Diagnosis and classification of diabetes mellitus. Geneve: World Health Organisation, non-communicable disease surveillance; 1999:1-59.

21. Greenland Statistics: Population in Greenland; 2012. Available from: http:// www.stat.gl

22. Ministry of Health in Greenland: Report on Health Care Reform. [Danish]. 2010 [cited 2011 Nov 2]. Available from: http://www.peqqik.gl. [in Danish] [Health care Reform 2010]

23. Malkani S, Mordes JP: Implications of using hemoglobin A1C for diagnosing diabetes mellitus. Am J Med 2011, 124:395-401.

24. Christensen DL, Witte DR, Kaduka L, Jørgensen ME, Borch-Johnsen K, Mohan V, Shaw JE, Tabák AG, Vistisen D: Moving to an A1C-based diagnosis of diabetes has a different impact on prevalence in different ethnic groups. Diabetes Care 2010, 33:580-582.

25. John WG, UK Department of Health Advisory Committee on Diabetes: Use of $\mathrm{HbA1C}$ in the diagnosis of diabetes mellitus in the UK. The implementation of World Health Organization guidance 2011. Diabet Med 2012, 29:1350-1357.

26. Syed IA, Khan WA: Glycated haemoglobin-a marker and predictor of cardiovascular disease. J Pak Med Assoc 2011, 61:690-695. 
27. Stratton IM, Adler Al, Neil HA, Matthews DR, Manley SE, Cull CA, Hadden D, Turner RC, Holman RR: Association of glycaemia with macrovascular and microvascular complications of type 2 diabetes (UKPDS 35): prospective observational study. BMJ 2000, 321:405-412.

28. Van Leiden HA, Dekker JM, Moll AC, Nijpels G, Heine RJ, Bouter LM, Stehouwer CD, Polak BC: Risk factors for incident retinopathy in a diabetic and nondiabetic population: the Hoorn study. Arch Ophthalmol 2003, 121:245-251.

29. Tapp RJ, Tikellis G, Wong TY, Harper CA, Zimmet PZ, Shaw JE, Australian Diabetes Obesity and Lifestyle Study Group: Longitudinal association of glucose metabolism with retinopathy: results from the Australian Diabetes Obesity and Lifestyle (AusDiab) study. Diabetes Care 2008, 31:1349-1354.

30. International Diabetes Foundation: Diabetes atlas Fifth edition. [cited 2012 Nov 8]. Available from: http://www.idf.org.

doi:10.1186/1758-5996-5-59

Cite this article as: Damsgaard and Pedersen: Use of glycosylated haemoglobin as diagnostic tool in Greenland: prevalence of diagnosed diabetes mellitus. Diabetology \& Metabolic Syndrome 2013 5:59.

\section{Submit your next manuscript to BioMed Central and take full advantage of:}

- Convenient online submission

- Thorough peer review

- No space constraints or color figure charges

- Immediate publication on acceptance

- Inclusion in PubMed, CAS, Scopus and Google Scholar

- Research which is freely available for redistribution 